\title{
Effects of crystalline growth on corrosion behaviour of nanocrystalline NiAl coating
}

\author{
M TAVOOSI*, H HEYDARI, A HOSSEINKHANI and B ADELIMOGHADDAM \\ Department of Material Engineering, Malek-Ashtar University of Technology, Shahin-Shahr, Isfahan 84156-83111, Iran
}

MS received 19 November 2014; accepted 16 March 2015

\begin{abstract}
In the current work, the effect of crystalline growth on the corrosion behaviour of nanocrystalline $\mathrm{NiAl}$ coating was investigated. In this regard, NiAl coatings with different crystalline sizes in the range of 20-110 nm were produced by mechanical alloying, high-velocity oxy-fuel processing (HVOF) and isothermal annealing at $600^{\circ} \mathrm{C}$ for $0-30 \mathrm{~h}$. The produced and annealed samples were characterized using $\mathrm{X}$-ray diffraction, scanning electron microscopy and transmission electron microscopy. The corrosion behaviours of coatings were examined in $\mathrm{NaCl} 3 / 5 \%$ electrolyte by potentiostat analysis. The nanocrystalline $\mathrm{NiAl}$ coating with the average crystalline size of about $20 \mathrm{~nm}$ and the porosity content of about $2 \%$ was successfully produced by mechanical alloying and HVOF processing. By annealing the coating, the NiAl crystalline sizes increased sharply, approaching a constant value of about $110 \mathrm{~nm}$. It was found that the corrosion resistance of nanocrystalline coating increased with the increase in the crystalline size.
\end{abstract}

Keywords. NiAl; nanostructure coating; crystalline growth; corrosion.

\section{Introduction}

Nanocrystalline materials, a class of materials with crystalline size smaller than $100 \mathrm{~nm}$, are synthesized by a variety of techniques such as severe plastic deformation, mechanical milling, inert gas condensation and electrodeposition processes. Interest in these materials is due to their high hardness, ductility, wear resistance and fatigue strength. ${ }^{1,2}$ Since these materials are characterized by high volume fraction of grain boundary (as much as 10-50\% of the total crystal volume), ${ }^{3}$ their corrosion behaviour may be different from coarse grain counterparts. However, good understanding of the relation between the corrosion property and microstructure of these materials is important for both prospective engineering applications and knowledge of fundamental physicochemical properties. ${ }^{4-6}$

$\mathrm{NiAl}$ intermetallic phase is being recognized as a kind of high-temperature structural material because of excellent chemical stability, high thermal conductivity, low density and high melting point. ${ }^{7,8}$ This compound often shows good corrosion and oxidation resistance due to the ability to form a dense, adherent and protective aluminium oxide layer. ${ }^{9-11}$ Although many efforts have been done through formation methods and the structural, physical and mechanical properties of nanocrystalline NiAl phase, ${ }^{12,13}$ there are few reports regarding the effect of crystalline size on the corrosion behaviour of this material. Thus, the aim of this work is to investigate the effect of crystalline size on the corrosion behaviour of nanocrystalline NiAl coating.

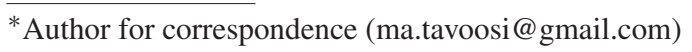

\section{Experimental}

Starting materials were elemental aluminium $(99.7 \%$ purity and particle size of $50-70 \mu \mathrm{m})$ and $\mathrm{Ni}(97.5 \%$ purity and particle size of $30-110 \mu \mathrm{m}$ ) powders. About $50 \mathrm{~g}$ of Ni and $\mathrm{Al}$ powder mixture, with the atomic ratio of $50: 50$, was placed in a hardened chromium steel vial of a planetary ball mill (Retsch PM100) and milled under argon atmosphere up to $90 \mathrm{~min}$ (ball to powder weight ratio of $10: 1$ and the rotation speed of $400 \mathrm{rpm}$ ). The coatings with the thickness of about $200 \mu \mathrm{m}$ were deposited onto the grit blasted low carbon steel substrate by high-velocity oxy-fuel processing (HVOF) spraying (powder rate of $80 \mathrm{~g} \mathrm{~min}^{-1}$, spray distance of $360 \mathrm{~mm}$, oxygen flow rate of $8301 \mathrm{~min}^{-1}$, fuel flow rate of $210 \mathrm{ml} \mathrm{min}^{-1}$ and fuel/oxygen volume ratio of 0.0253 ). The fuel was modified aviation turbine kerosene. Annealing of the samples was performed at $600^{\circ} \mathrm{C}$ for different periods of time $(0-30 \mathrm{~h})$ at ambient atmosphere.

$\mathrm{X}$-ray diffractometer was used to study the structure of milled, deposited and annealed samples. A Philips X-PERT MPD diffractometer was used for X-ray diffraction (XRD) measurements using filtered $\mathrm{Cu} \mathrm{K} \alpha$ radiation $(k=0.1542$ $\mathrm{nm})$. The XRD patterns were recorded in the $2 \theta$ range of $30-80^{\circ}$ (step size of $0.03^{\circ}$ and time per step of $1 \mathrm{~s}$ ). The Scherrer method ${ }^{14}$ was used to evaluate the crystallite size of NiAl phase. The microstructures of as-sprayed and annealed coatings were observed by scanning electron microscopy (SEM) in a Philips XL30 SEM at an acceleration voltage of $30 \mathrm{kV}$. Sample preparation procedure for microstructural observations was carried out by the conventional metallographic techniques. High-resolution 
transmission electron microscopy (HR-TEM) in a Jeol-2010 microscope at an accelerated voltage of $200 \mathrm{kV}$ was also used for microstructural investigations.

To determine the corrosion resistance of the coating, polarization corrosion testing method by a potentiostat system (EG\&G Model 273A) was used. The solution and the reference electrode were $\mathrm{NaCl} 3 / 5 \%$ and $\mathrm{Ag} / \mathrm{AgCl}$, respectively (with the scan rate of $1 \mathrm{mV} \mathrm{s}^{-1}$, the initial potential of -250 $\mathrm{mV}$ and the final potential of $250 \mathrm{mV}$ ).

\section{Results and discussion}

\subsection{Preparation of nanocrystalline NiAl coating}

Figure 1 shows the XRD patterns of $\mathrm{Ni}_{50} \mathrm{Al}_{50}$ powder mixture before and after $90 \mathrm{~min}$ of milling times. The XRD patterns of the un-milled powder mixture showed diffraction peaks of the crystalline $\mathrm{Ni}$ and $\mathrm{Al}$ phases. Increasing the milling time led to the disappearance of the $\mathrm{Ni}$ and $\mathrm{Al}$ peaks, while $\mathrm{NiAl}$ peaks began to appear. Complete transformation of elemental $\mathrm{Ni}$ and $\mathrm{Al}$ powder mixture to the NiAl intermetallic phase occurred after $90 \mathrm{~min}$ of milling. This result showed that the reaction between $\mathrm{Al}$ and $\mathrm{Ni}$ was promoted by the extensive $\mathrm{Ni} / \mathrm{Al}$ interface areas as well as the short-circuit diffusion paths provided by the large number of defects such as dislocations and grain boundaries introduced during ball milling. ${ }^{1} \mathrm{Hu}$ et $a l^{15}$ reported that complete transformation of $\mathrm{Ni}+\mathrm{Al}$ to NiAl compound during mechanical alloying (MA) occurred after $240 \mathrm{~h}$ which is much longer than MA time

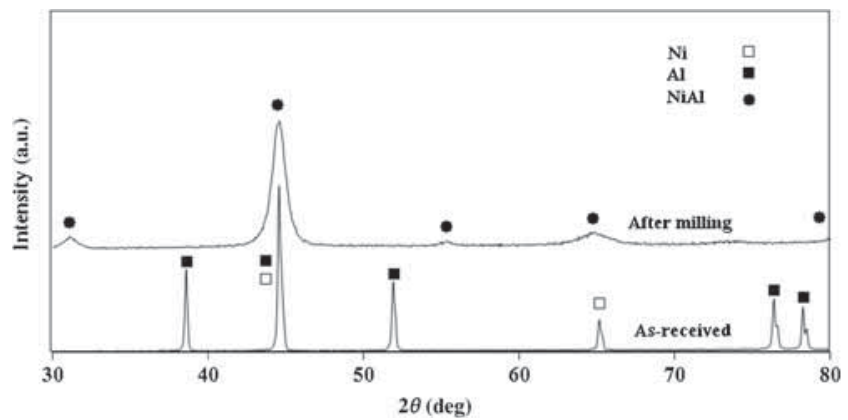

Figure 1. XRD patterns of $\mathrm{Ni}_{50} \mathrm{Al}_{50}$ powder mixture before and after $90 \mathrm{~min}$ of milling times.

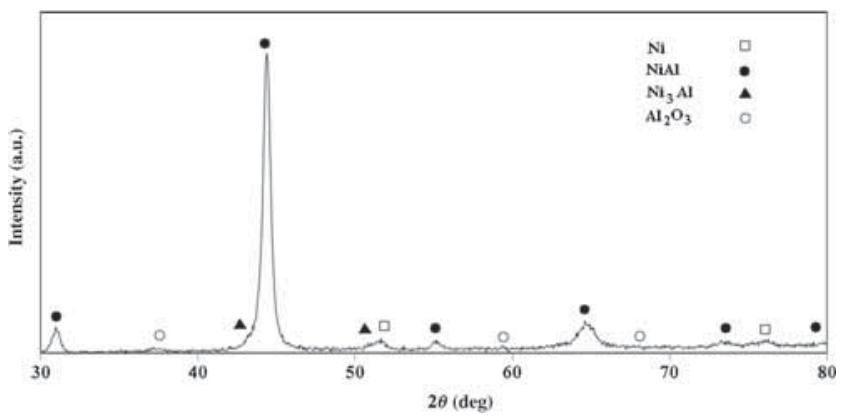

Figure 2. XRD pattern of as-deposited nanocrystalline NiAl coating. obtained in the present study. This discrepancy can be due to the different mill machines used. The average crystalline size of the produced $\mathrm{NiAl}$ phase in this study was estimated about $10 \mathrm{~nm}$.

The XRD pattern of the as-deposited NiAl coating is presented in figure 2. According to this figure, besides the NiAl main peaks, several additional, small, broad peaks appeared in the XRD pattern. These peaks were identified as $\mathrm{Ni}, \mathrm{Ni}_{3} \mathrm{Al}$ and $\mathrm{Al}_{2} \mathrm{O}_{3}$ phases. Figure 3 shows the high-magnification

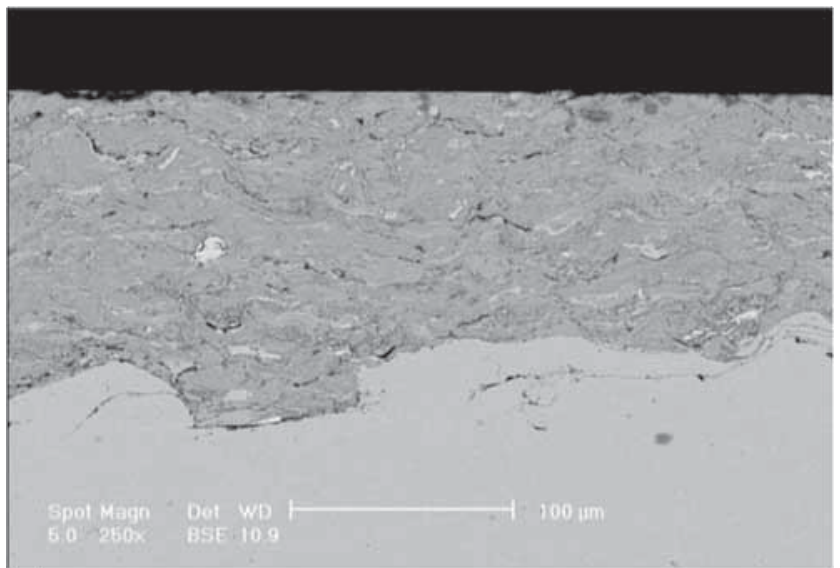

(a)

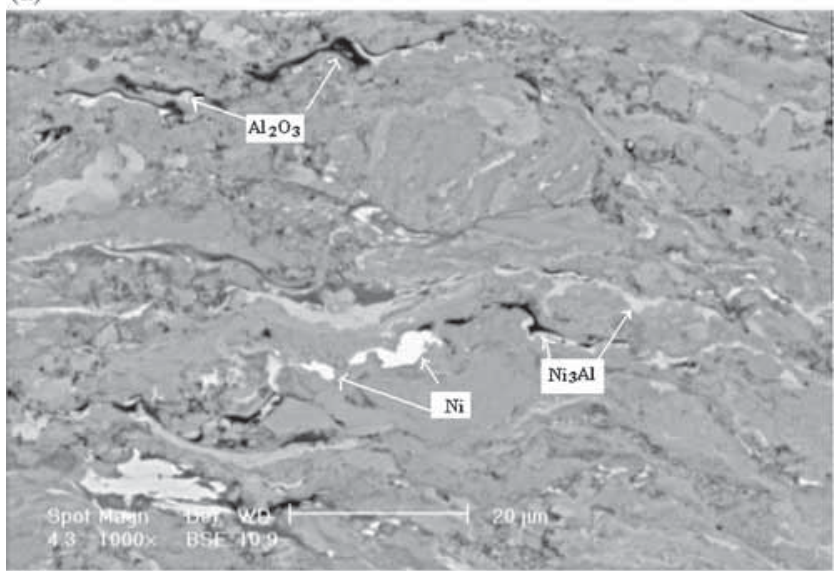

(b)

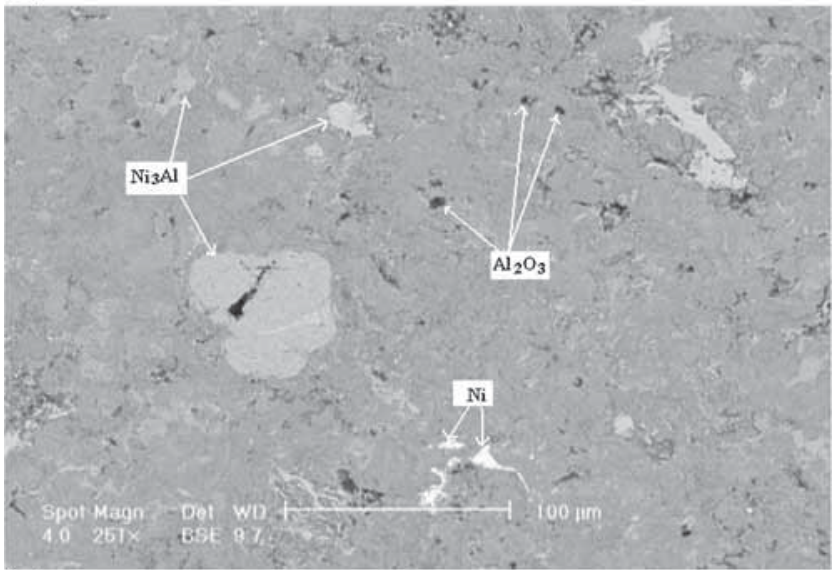

(c)

Figure 3. Cross-section (a and b) and surface (c) SEM micrographs of as-deposited $\mathrm{NiAl}$ coating. 
SEM photographs of thermal sprayed coating. The coating layers generally exhibited distinct splats or lamellae as a result of impact effects during the thermal spray process. As seen, the overall coating microstructure was homogeneous and uniform with little closed pores along lamella boundaries (about 2\%). According to XRD and energy-dispersive spectroscopy (EDS) analysis, these micrographs consist of four different phases: $\mathrm{NiAl}$ (dark grey matrix), Ni (white phase), $\mathrm{Ni}_{3} \mathrm{Al}$ (light grey phase) and $\mathrm{Al}_{2} \mathrm{O}_{3}$ (black phase). It can be demonstrated that during $\mathrm{HVOF}$ processing, in some regions of $\mathrm{NiAl}$ phase depletion of $\mathrm{Al}$ atoms occurred due to oxidation, thereby the $\mathrm{Al}$ content reduced to the range of stability of $\mathrm{Ni}_{3} \mathrm{Al}$ and $\mathrm{Ni}$ phases. ${ }^{16}$ The crystalline size of $\mathrm{NiAl}$ coating was estimated via TEM (figure 4) and XRD to be about $20 \mathrm{~nm}$. This confirms that $\mathrm{NiAl}$ coating has retained the nanocrystalline structure which is typically considered for crystalline size below $100 \mathrm{~nm}$.

\subsection{Annealing the nanocrystalline coating}

In order to investigate the phase evolution during annealing, the as-deposited coating was annealed under oxidizing

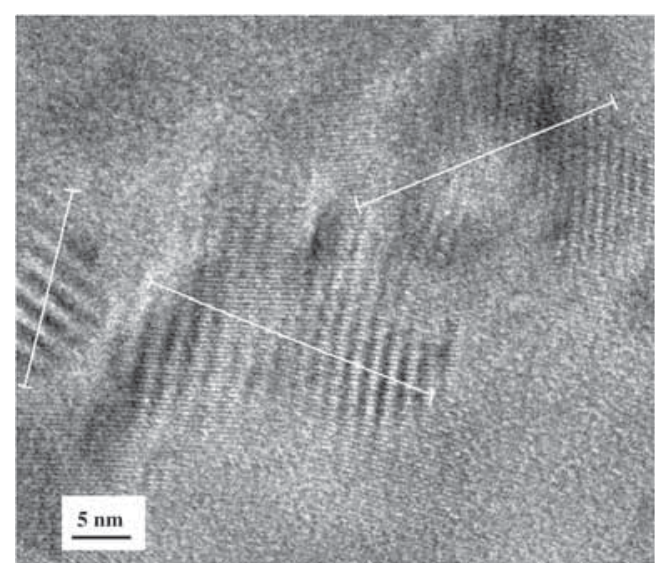

Figure 4. TEM image of as-deposited nanocrystalline NiAl coating.

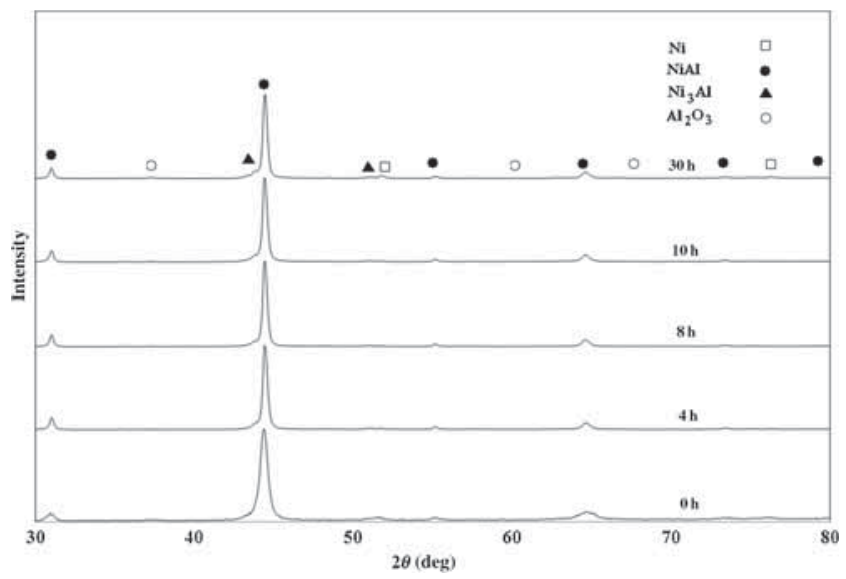

Figure 5. XRD patterns of produced $\mathrm{NiAl}$ coatings before and after annealing at $600^{\circ} \mathrm{C}$ for different periods of time. condition. The XRD patterns of coating after annealing at $600^{\circ} \mathrm{C}$ for different periods of time are shown in figure 5 . As can be seen, during isothermal annealing, only narrowing of the NiAl peaks with remarkable increase in their intensities occur as a result of the increase in the crystalline sizes and decrease in the lattice strains. Figure 6 shows the SEM micrographs of annealed sample at $600^{\circ} \mathrm{C}$ for $30 \mathrm{~h}$. As seen,

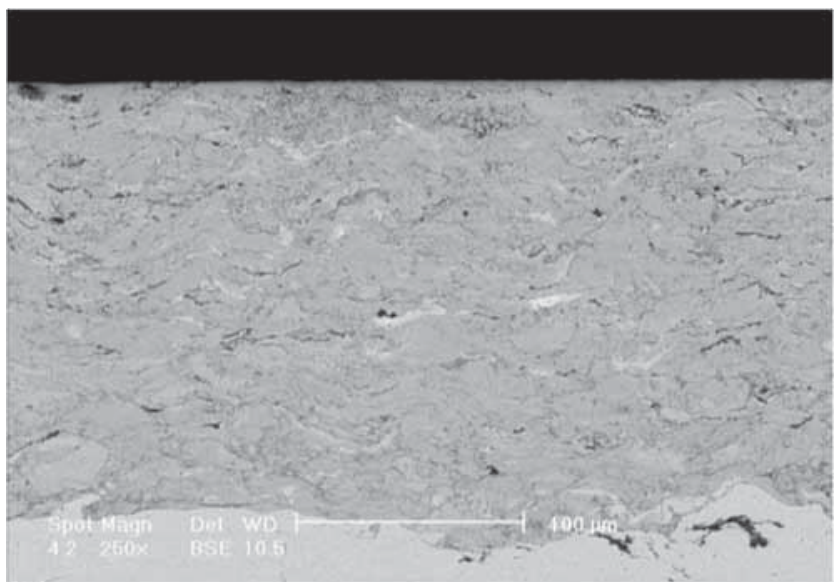

(a)

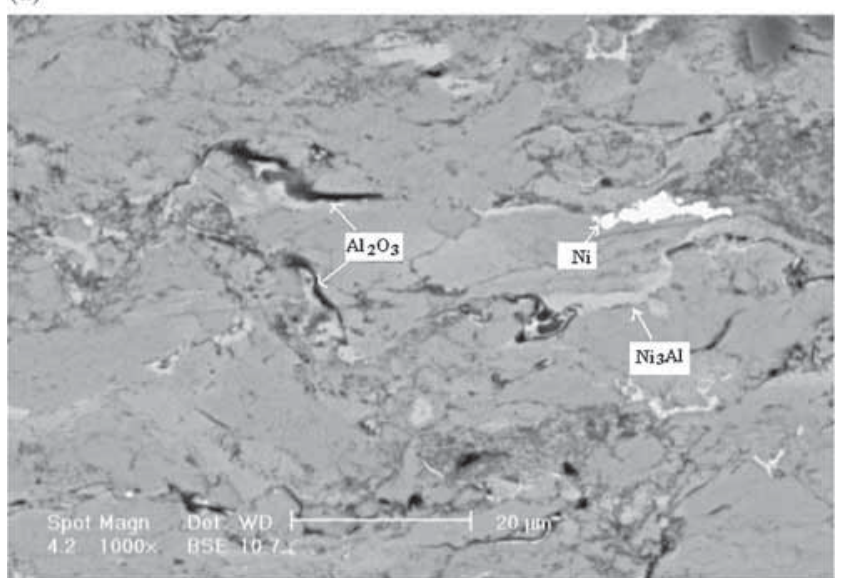

(b)

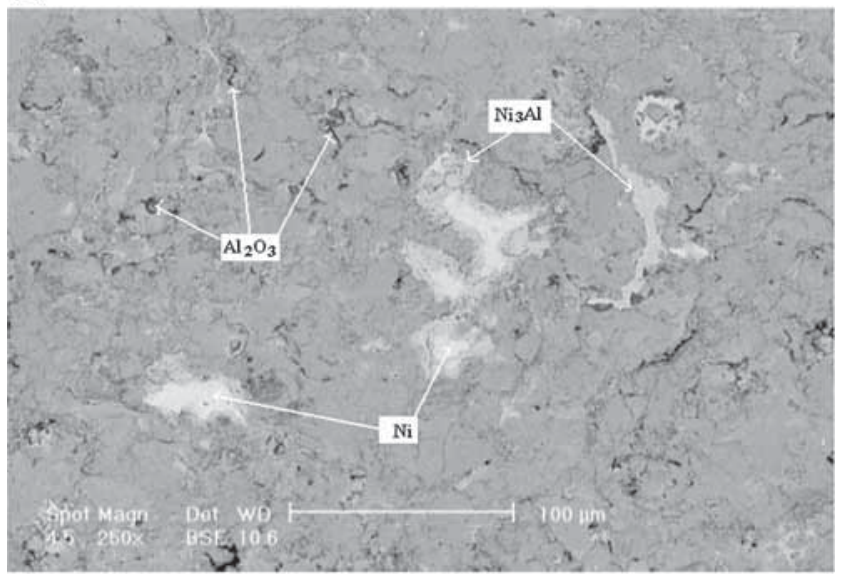

(c)

Figure 6. Cross-section (a and b) and surface (c) SEM micrographs of as-deposited $\mathrm{NiAl}$ coating after annealing at $600^{\circ} \mathrm{C}$ for $30 \mathrm{~h}$. 
there is no significant difference between these micrographs and the micrographs of coating before annealing (figure 3 ). Thus, during isothermal annealing in oxidation atmosphere at $600^{\circ} \mathrm{C}$, gradual grain refinement was the only considerable change that occurred in the coating and no detectable reaction took place. In fact, the NiAl compound has good oxidation resistance due to the ability of this material to form a dense, adherent and protective aluminium oxide layer. ${ }^{17}$ Moreover, the EDS analysis of annealed samples confirmed that $\mathrm{Fe}$ atoms could not diffuse from substrate to coating and the composition of coatings remained constant during annealing.

The crystalline sizes of the NiAl coating, determined by the Scherrer equation, as a function of annealing time is shown in figure $7 \mathrm{a}$. It can be seen that substantial crystalline growth takes place at the initial annealing stage. As the annealing time is further increased up to $30 \mathrm{~h}$, the crystalline growth ceases to reach an ultimate grain size of approximately $110 \mathrm{~nm}$ regardless of the annealing time. Figure $7 \mathrm{~b}$ shows a typical TEM micrograph of the nanocrystalline $\mathrm{NiAl}$ coating annealed for $30 \mathrm{~h}$. It was found that the crystalline size determined by TEM is slightly larger than that determined by XRD.

The relationship between average crystalline size and annealing time is usually expressed in the form of ${ }^{18}$

$$
d^{n}-d_{0}^{n}=K t
$$

or

$$
d-d_{0}=K t^{1 / n}
$$

where $d_{0}$ is the initial grain size, $d$ the grain size following the annealing time $t, K$ a constant, and $n$ the grain growth exponent. According to equation (2), a plot of $\log \left(d-d_{0}\right) v s$. $\log (t)$ will have a slope equal to $1 / n$. By attention to figure 8 , the grain growth exponent $(n)$ for nanocrystalline NiAl coating was estimated to be about 2, which is strongly lower

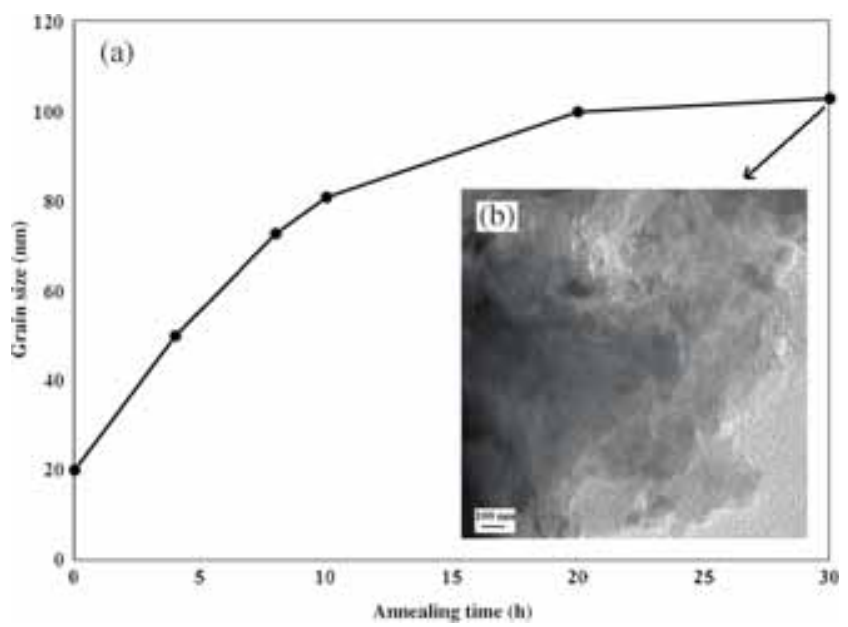

Figure 7. Average crystalline sizes of the NiAl coatings as a function of annealing time (a) and TEM images of as-deposited NiAl coating after annealing at $600^{\circ} \mathrm{C}$ for $30 \mathrm{~h}(\mathbf{b})$. than the grain growth exponent $(n=6)$ in the conventional coarse-grained NiAl. ${ }^{18}$ In fact, the presence of $\mathrm{Ni}, \mathrm{Ni}_{3} \mathrm{Al}$ and $\mathrm{Al}_{2} \mathrm{O}_{3}$ phases as well as porosity in microstructure, reduce the overall mobility of the boundaries in coating. ${ }^{1}$ The above results suggest that the nanocrystalline $\mathrm{NiAl}$ coating exhibits crystalline size stability.

\subsection{Corrosion behaviour of coatings}

The polarization curves of $\mathrm{NiAl}$ nanocrystalline coating after different annealing times at $600^{\circ} \mathrm{C}$ are shown in figure 9. The changes of corrosion potential and corrosion current density of these samples $v s$. annealing time are also presented in figure 10. According to these figures, annealing the produced coating led to change in corrosion behaviour. The corrosion potential and current density of as-deposited coating is about $-967 \mathrm{mV}$ and $6.172 \mu \mathrm{A} \mathrm{cm}{ }^{-2}$, respectively. It can be observed that, by increasing the annealing time (increasing the grain size to $110 \mathrm{~nm}$ ), the corrosion potential negatively

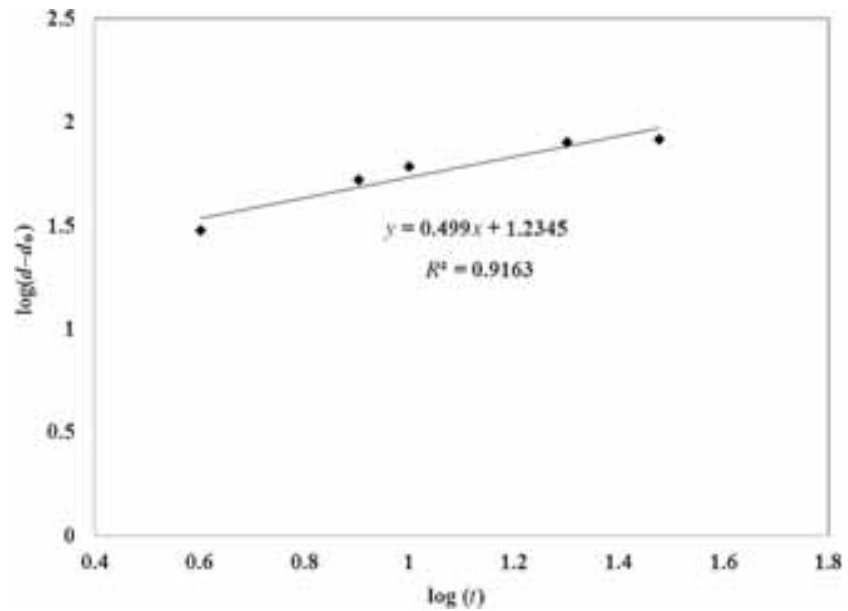

Figure 8. Plot of $\log \left(d-d_{0}\right)$ vs. $\log (t)$ for nanocrystalline NiAl coating.

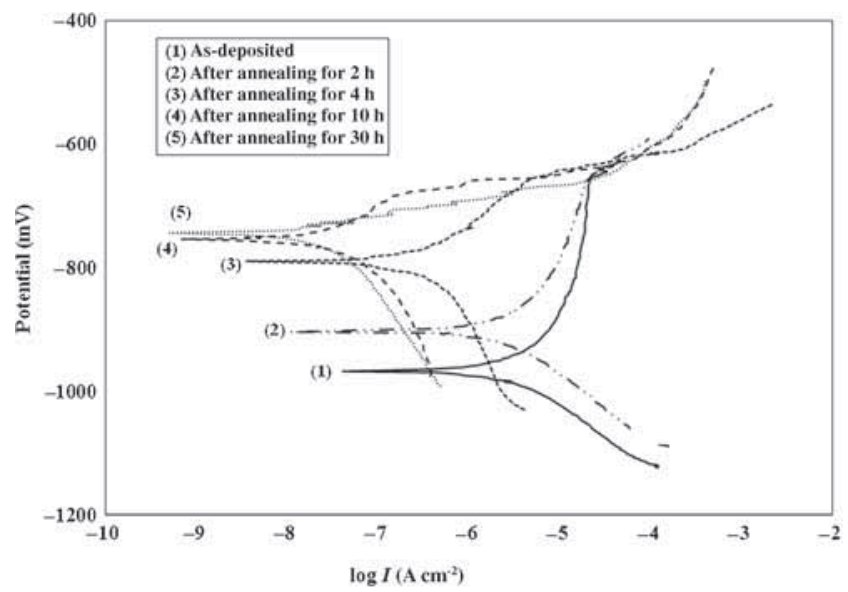

Figure 9. Polarization Tofel curves of as-deposited coating before and after annealing at $600^{\circ} \mathrm{C}$ for different periods of time. 


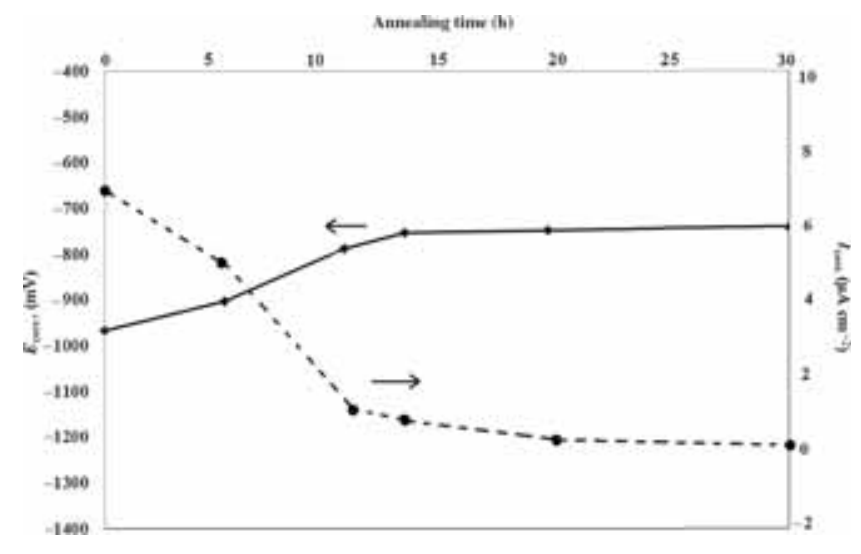

Figure 10. Corrosion potential and corrosion current density of nanocrystalline $\mathrm{NiAl}$ coating after annealing at $600^{\circ} \mathrm{C}$ for different periods of time.

shifts from -967 to $-790 \mathrm{mV}$. In this condition, the corrosion current density decreases evidently from 6.172 to $0.022 \mu \mathrm{A} \mathrm{cm}{ }^{-2}$. By considering all above features, it can be concluded that the nanorystalline $\mathrm{NiAl}$ with the larger crystalline size should exhibit better corrosion resistance in $3.5 \% \mathrm{NaCl}$ solution. The enhanced corrosion resistance with the increase in the crystalline sizes can be attributed to the reduction of volume fraction of grain boundaries and triple junctions as active sites for corrosion attack. ${ }^{19-21}$

\section{Conclusions}

The nanostructure NiAl intermetallic coating with the average crystalline size of about $20 \mathrm{~nm}$ and the porosity content of about $2 \%$ was successfully produced by MA and $\mathrm{HVOF}$ processing. Besides the main $\mathrm{NiAl}$ phase, several additional phases including $\mathrm{Ni}, \mathrm{Ni}_{3} \mathrm{Al}$ and $\mathrm{Al}_{2} \mathrm{O}_{3}$ were also developed in the coating due to the slight oxidation of powders during the HVOF process. By annealing the produced coating, the NiAl crystalline sizes increased sharply, approaching a constant value of about $110 \mathrm{~nm}$. The corrosion resistance of $\mathrm{NiAl}$ coating increased with the increase in the annealing time due to the reduction of volume fraction of grain boundaries and triple junctions as active sites for corrosion attack.

\section{References}

1. Suryanarayan C 2001 Prog. Mater. Sci. 461

2. Kumar K S, Swygenhoven H and Suresh S 2003 Acta Mater. 515743

3. Kim H S and Bush M B 1999 Nanostruct. Mater. 11361

4. Ralston K D, Fabijanic D and Birbilis N 2011 Electrochim. Acta 561729

5. Liu K T and Duh J G 2008 J. Electroanal. Chem. 61845

6. Argade G R, Panigrahi S K and Mishra R S 2012 Corros. Sci. $\mathbf{5 8} 145$

7. Enayati M H, Karimzadeh F, Tavoosi M, Movahedi B and Tahvilian A 2011 J. Therm. Spray Technol. 20440

8. Stoloff N S, Liu C T and Deevi S C 2000 Intermetallics 81313

9. Morsi K 2001 Mater. Sci. Eng. A 2991

10. Mashreghi A and Moshksar M M 2009 J. Alloys Compd. 482 196

11. Deshpande S, Sampath S and Zhang H 2006 Surf. Coat. Technol. 2005395

12. Haff G R and Schulson E M 1982 Mater. Trans. A 131563

13. Zhou L Z, Guo J T, Li G S, Xiong L Y, Wang S H and Li C G 1997 Mater. Des. 18373

14. Cullity B D 1956 Elements of X-ray diffraction (AddisonWesley Publishing Company)

15. Hu W, Li M and Fukumoto M 2008 Mater. Sci. Eng. A 4781

16. Hearley J A, Little J and Sturgeon A J 2000 Surf. Coat. Technol. 123210

17. Albiter A, Espinosa-Medina M A, Gonzalez-Rodriguez J G and Perez R 2005 Int. J. Hydrogen Energy 301311

18. Zhou L Z and Guo J T 1999 Scr. Mater. 40139

19. Wang L, Lin Y, Zeng Z, Liu W, Xue Q, Hu L and Zhang J 2007 Electrochim. Acta $\mathbf{5 2} 4342$

20. Vinogradov A, Mimaki T and Hashimoto D S 1999 Scr. Mater. 41319

21. Fu L, Yang J, Bi Q and Liu W 2011 Mat. Sci. Appl. 2435 